\title{
V. V. Acharya, S. van Nieuwerburgh, M. Richardson, and L. J. White (2011): Guaranteed to Fail: Fannie Mae, Freddie Mac and the Debacle of Mortgage Finance, Princeton University Press. 176 pages, USD 24.95
}

\author{
Rico von Wyss
}

Published online: 5 January 2013

(C) Swiss Society for Financial Market Research 2013

The government-sponsored enterprises (GSEs) Fannie Mae and Freddie Mac are engaged in a highly specialized business-to-business segment of mortgage finance. In fact, they are so specialized that it was only the financial crisis that made them, as well as certain specifics of the U.S. mortgage market, into "household names." Guaranteed to Fail thoroughly describes the role played by the two GSEs in the recent crisis.

The book delivers what the subtitle promises. This is a book about Fannie Mae and Freddie Mac and their role at the origin of the recent financial crisis, which occurred in the housing market. This is neither a book about the financial crisis in general, nor about the role of other players in the market such as investment banks, rating agencies, central banks, government, political parties, or whoever is blamed for having contributed to the crisis.

Guaranteed to Fail is at its best when explaining how the GSEs developed over time, how their mandate has been expanded, and which incentives have been (and still are) at work. Chapter 1 describes securitization in the U.S. housing market and the good intentions behind the founding of the GSEs. The following chapters detail the expansion of their business into subprime mortgages and their rapid growth, related also to residential mortgage investments financed by debt issues. This made the GSEs similar to highly leveraged hedge funds. With the burst of the housing bubble, the GSEs essentially came under government ownership and management. Chapter 7 looks at housing markets around the world, revealing that although other real estate market systems are not crisis proof either, there is absolutely no need for U.S.-style GSEs to make a mortgage market work. The book remains comparably superficial on

R. von Wyss $(\varangle)$

University of St.Gallen (HSG), Swiss Institute of Banking and Finance,

Rosenbergstrasse 52, 9000 St. Gallen, Switzerland

e-mail: heinrich.vonwyss@unisg.ch 
what the final cost for the taxpayer may be. Only the Prologue and Chapter 8 on a possible reform of the GSEs give some estimates. The authors favor an orderly and comparably slow winddown of the GSEs' operations in light of their huge (USD 1.7 trillion) assets. However, keeping in mind all possible subsidies and the corresponding political incentives described in Chapter 9, I am not sure whether this is a feasible path to pursue. It might be better to make a painful break while there is still some pressure for change than to draw out the agony. Otherwise, we might end up with the same system as before the crisis.

The authors of Guaranteed to Fail are professors of finance or economics at the New York University's Stern School of Business. In writing this book, they drew on their own research and decades of experience in financial markets. They combine in an ideal way research and political consulting, resulting in an easy-to-read book that nevertheless has the necessary in-depth analysis. The book is rich with quotes from the past suggesting that everybody should have seen the imminent disaster. But, we always know better after the fact; before, it is difficult to disentangle the signals from the noise.

Whether the allegories to Frankenstein, the Devil's Cigarette Lighter, Julius Caesar, and painkillers with side-effects really help in understanding the U.S. mortgage market is probably a matter of taste. In any case, Guaranteed to Fail is a topical book that tells us how we created a mess that will need our attention for many years to come. 